\title{
Induced Contention Therapy and functional bandage in children with cerebral palsy: Case report
}

\author{
Priscila Oliveira de Bortoli ${ }^{1}$, Letícia Ramos Dutra ${ }^{1}$, Rodrigo José Knabben², Claudia Mirian de Godoy \\ Marques ${ }^{1}$, Micheli Martinello ${ }^{3}$. \\ 1,Universidade do Estado de Santa Catarina - UDESC, Florianópolis (SC) - Brazil; ${ }^{2}$ Universidade Federal de Santa Catarina - UFSC, Florianópolis, \\ (SC) - Brazil; ${ }^{3}$ Universidade Federal de São Paulo - UNIFESP, São Paulo (SP) - Brazil.
}

\begin{abstract}
Background: The decrease in the manual activity of hemiparetic children, affects their functionality and independence. Among the therapies used to improve manual function, there is Induced Contention Therapy (ICT) and functional bandaging (FB). Such approaches aim to improve the use and decrease the disuse learned from the upper limb in subjects with hemiparesis. Objective: Identify the effect of ICT, associated with the application of functional bandaging on the affected upper limb, in the function of the upper limb and on the handgrip of a child with spastic hemiplegic cerebral palsy. Methods: A 5-year-old child received ICT for three hours daily for three consecutive weeks associated with FB in the right upper limb. The use of the upper limb was evaluated using the Pediatric Upper Extremity Motor Activity Log (PMAL) scale, the acquisition of new motor standards using the Inventory of New Motor Activities and Program (INMAP) scale, the motor skill by the Pediatric Arm Functional Test (PAFT) and the handgrip strength by the dynamometer. Results: There was an improvement in the quantity and quality of use of the paretic upper limb after the application of ICT, which remained after one month of therapy. In addition, it was observed the acquisition of new motor skills and improvement in handgrip strength. Conclusion: This study had a potential positive effect on handgrip strength, functionality and quality of use of the paretic upper limb of a child with spastic CP after the application of ICT associated with functional bandaging.

Keywords: Child; Case Study; Cerebral Palsy; Rehabilitation.
\end{abstract}

\section{BACKGROUND}

Impairments in disability and difficulty in typical functioning are consequences of Cerebral Palsy $(\mathrm{CP})$, featuring postural deficit in spastic hemiparesis, which is responsible for the consequent movement restriction and functional asymmetries $^{(1,2)}$. Limitations in the pattern of movement and posture interfere with the postural control mechanism and motor capacity, and therefore have an impact on functional performance, motor milestones, as well as on daily activities ${ }^{(3-7)}$. Specifically, about manual function and postural control for manual activities, degrees of difficulty are demonstrated $^{(8,9)}$, which are associated with muscle tone, posture ${ }^{(10)}$, balance, coordination, decreased strength and loss of selective motor control ${ }^{(11)}$.

There are countless essential daily activities that involve handgrip, being able to enable an independent and quality life, however, frustration behaviors observed in children when trying to use the affected extremity, lead them to make greater use of the non-affected hand side, a phenomenon that can be described as learned disuse ${ }^{(8,9,12)}$. Once changes in manual skills are present, there is Induced Contention Therapy (ICT), which is one of the most developed approaches in upper limb rehabilitation ${ }^{(13,14)}$. Children with hemiparetic CP tend to the significantly improve, with an increase in the functional use of the affected upper limb ${ }^{(14-18)}$, the improvement of bimanual skills ${ }^{(19)}$, the acquisition of new patterns of behavior ${ }^{(20)}$, the improvement in manual dexterity and sensorimotor discrimination ${ }^{(21)}$, the improvement in the quantity and quality of use of the affected upper limb ${ }^{(17)}$, and improvement in the spontaneity of use of the most affected limb, with increased agility and functional ability ${ }^{(22)}$, which consequently results in an increase in the performance of tasks of daily living ${ }^{(14,23,24)}$.

Increased spontaneity in the use of the affected limb suggests that this type of intervention promotes motivation and perception of the possibilities of using the affected limb when performing daily tasks, which reduces learned disuse ${ }^{(14,23,25)}$. In addition, it is recently used as an adjunct to a therapeutic program in the treatment of neurofunctional diseases, the functional bandage $(F B)^{(26-30)}$, restricting abnormal posture and decreasing spasticity in children with $\mathrm{CP}^{(26,31,32)}$. Thus, in order to obtain a better use of voluntary coordination and manual control, the objective of this study was to identify the effect of ICT associated with the application of FB in the most affected upper limb (UL), according to manual functionality, of a child with spastic hemiparetic $C P$. 


\section{METHODS}

This case report is characterized as a clinical trial, with intensive intervention by ICT associated with $\mathrm{FB}$ in a child diagnosed with $\mathrm{CP}$, of the spastic hemiparesis type with left laterality, Gross Motor Function Classification System (GMFCS) level $\mathrm{V}$ and Manual Ability Classification System (MACS) level II, characterizing the degree of active movement, impairment of active movement of the upper limb as two.

\section{Study sample}

A five-year-old male child with hemiparetic cerebral palsy (HCP), selected in an intentional non-probabilistic way, complaining of asymmetric use of the upper limbs, was included in the study. The child was available for three-hour daily care for three consecutive weeks and did not have disabling language changes, comprising simple orders. In addition to clinical criteria, motor criteria for inclusion of the child were: presence of active movement in the shoulder, elbow, wrist and fingers; trunk control sufficient to release upper limbs for activities; and absence of disabling involuntary movement ${ }^{(33)}$.

\section{Assessment Instruments}

An anamnesis form was used to characterize the sample, containing data related to the person responsible for the child (name, age, date of birth, sex, marital status, profession, level of education), gestational history (prenatal, pregnancy complications, gestational duration), data regarding the child (name, age, date of birth, sex, birthplace, use of medication) and occurrence of neonatal complications during the first year of life. The handgrip strength was measured using the hand dynamometer Deyard EH101 Electronic Hand Dynamometer, UK. To perform the test, the recommendation of the American Society of Hand Therapists (ASHT) was used, in which it is recommended that the child remain comfortably seated, positioned with the adducted shoulder, the elbow flexed at $90^{\circ}$, the forearm in a neutral position and, finally, the position of the wrist can vary from $0^{\circ}$ to $30^{\circ}$ in length. The child was asked to perform the greatest possible strength in each hand, with a demonstration and familiarization with the instrument and the test system always beforehand ${ }^{(34)}$. The maximum peak was recorded through three measurements on the most compromised limb for calculating the arithmetic mean, respecting a period of 20 seconds of rest between two measurements on the same side ${ }^{(35)}$.

To assess functionality, the Pediatric Upper Extremity Motor Activity Log (PMAL), Pediatric
Arm Functional Test (PAFT) and Inventory of New Motor Activities and Program (INMAP) scales were used, and the ICT protocol was followed according to age ${ }^{(36)}$. PMAL is a structured interview used for children aged 2 to 8 years; the responsible is asked how often it is used and what is the quality of the movement of the most affected upper limb during the performance of daily tasks.

The questionnaire consists of 26 tasks and features a Frequency Scale (FS) and a Quality Scale (QS), both scored from 0 to 5 . In FS, the person responsible should assign the score considering that: $0=$ does not use the affected UL to perform a certain task; 1 = very rarely; $2=$ rarely; $3=$ sometimes (half the time the task was performed); 4 = frequently; and $5=$ balanced use of UL (normal) $(10,11)$. In the QS, the score from 0 to 5 was equivalent: $0=$ no use; $1=$ very poor use, the most affected UL not functional, just moving; 2 = poor use of the most affected extremity, requiring assistance; $3=$ moderate use, but with great difficulty; $4=$ almost normal use, with little difficulty; and $5=$ normal use. The Pediatric Arm Functional Test (PAFT) consists of 26 items, which are separated into unilateral (17 tasks) and bilateral (9 tasks) activities. Each item presents its description and initial position, the evaluation is filmed and then scored by a blind evaluator. The Inventory of New Motor Activities and Program (INMAP) corresponds to the records of new motor patterns, never observed before. 10 motor programs and 22 activities of daily living are evaluated, same as PMAL.

\section{Data collection procedure}

This research was approved by the Human Research Ethics Committee of the Universidade do Estado de Santa Catarina, with CAAE number 60009516.3.0000.0118. The Free and Informed Consent Terms were presented and both the mother and the child agreed to be part of the research. After the application of the identification form and anthropometric measurements, the subject was prepared to assess the handgrip strength, using the dynamometry technique. To obtain biomechanical records, the child was instructed to remain seated, with forearm supinated and supported on a flat surface, and elbow at $90^{\circ}$ of flexion ${ }^{(34,35,37)}$. The handgrip movement was performed with the most affected upper limb, three repetitions were requested at the highest speed the child was able to perform, with intervals of 20 seconds between each one.

According to the ICT Protocol (Figure 1), the pre-intervention was performed through the participation contract with the person in charge, to 
compromise the presence in the sessions, as well as in the use of restraint in the home environment and carrying out the tasks established by the therapist, the physical examination, the application of complete PMAL, application of PAFT and INMAP, and the placement of a sling for the least affected limb. During the intervention period, the child received task-oriented training with supervision for 3 hours a day, where two training procedures were used, shaping - a training method based on the training of motor behavior or task practice - task less structured and specific, working the member globally ${ }^{(12,15,36)}$. From the $1^{\text {st }}$ day to the $13^{\text {th }}$ day of training were carried out: the application of 11 items on the PMAL / TMAL quality scale (1-11 or 12-22), new motor patterns verified by INMAP, three hours of training, and determination of homework. The tasks were chosen according to the TMAL score and performed with play materials suitable for the patient's reality. On the 14th day of training, the sling was removed and the three-hour training was focused on bimanual functions and guidelines, in addition the INMAP was applied to verify new motor patterns. On the 15th training day, complete PMAL / TMAL was applied to verify the use of the upper limb without a sling. In accordance with the ICT protocol, evaluations were carried out in the pre-treatment, during treatment (daily by PMAL / TMAL), and after training, connection one-month post-training. The total duration of therapy was three hours daily, five days a week, for three weeks. The frequency and quality of daily use of the most affected UL were assessed by the Pediatric Upper Extremity Motor Activity Log (PMAL) and the motor ability was assessed by the Pediatric Arm Function Test (PAFT). In addition, the acquisition of new motor standards by the Inventory of New Motor Activities and Program (INMAP).

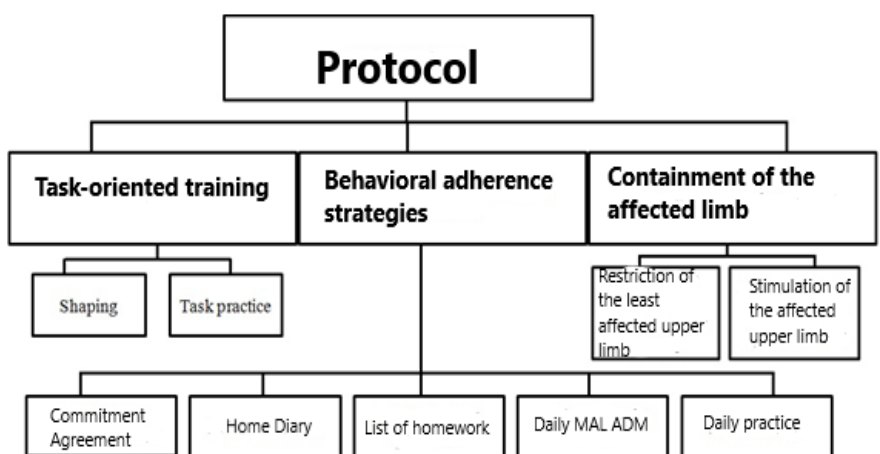

Figure 1. Flowchart to represent the principles of Induced Containment Therapy followed in the study

The application of FB was performed in the most affected upper limb, for scapular stabilization and palmar stabilization, favoring supination and wrist and finger extension (Figure 2) since hemiparetic patients present a flexor pattern of the upper limb with internal rotation and adduction of the shoulder, elbow flexion, wrist and finger pronation and flexion ${ }^{(34,35)}$. This pattern installs due to the spasticity present in the antigravity muscles, giving rise to abnormal posture and movement patterns $^{(34,35)}$. The first application was on day one of treatment, after an initial test in case of elastic band allergy; the child remained with the tape until it began to spontaneously release, after removal it was waited for at least 24 to 48 hours for replacement, avoiding skin lesions ${ }^{(38)}$. The biomechanical evaluation was carried out before and after treatment. The child underwent three evaluations in total: one day before the start of treatment (A1) in which the biomechanical evaluation was performed and the application of the PAFT, INMAP and PMAL scales, last day of therapy in which all scales were reapplied and the biomechanical assessment of handgrip strength (A2) was redone and 30 days after the end of the ICT in which the PMAL scale (A3) was reapplied.

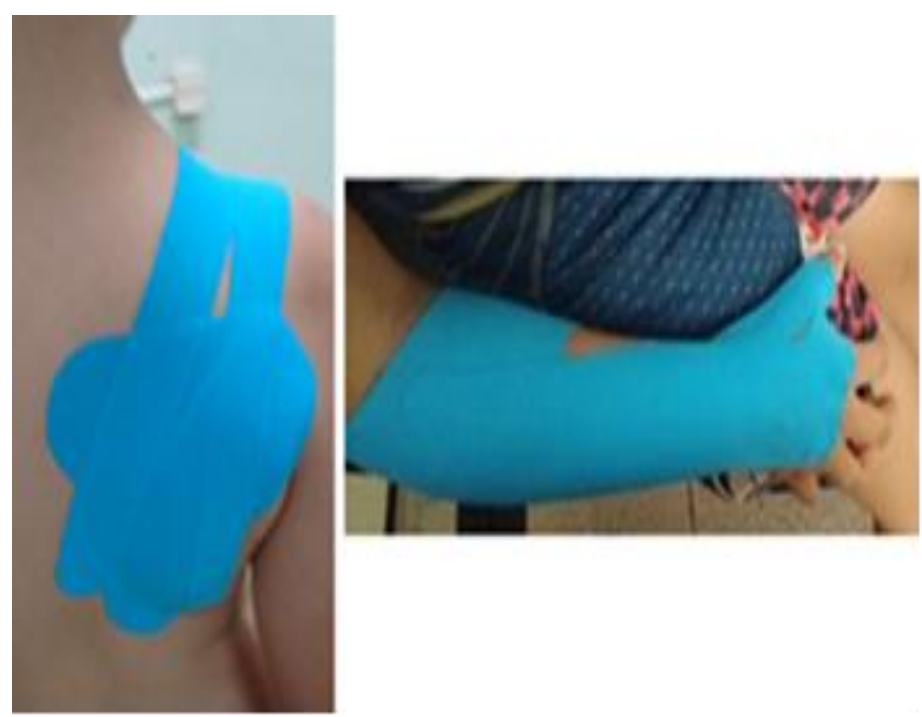

Figure 2. Application of Functional Bandaging.

\section{Data analysis}

The data from the clinical evaluation by the PMAL were evaluated using a Frequency Scale (FS) and a Quality Scale (QS), both of which score from zero to five. For FS zero it demonstrates the deficient use of the upper limb in a given task and five to the use of the affected upper limb in the same proportion as the non-affected limb. The total score was obtained, adding up the score for each item and dividing by total number of tasks, in the case of tasks impossible to be performed; the question was eliminated from all PMAL sessions, and the score was defined by the number of valid and answered questions. 
The data obtained by PAFT were determined from the child's spontaneity in performing the task with the affected limb. In the tasks in which the patient used the non-affected limb, at the end of the test it was repeated and pointed at the affected limb, in the bilateral tasks, the subject was instructed to use both limbs.

The scale indicated whether the child performed the movement during the first or second task administration; as for the functional scale, it varies from zero to five, which corresponds to the child not making any attempt with the affected limb, or doing the activity normally with the affected limb, respectively. The score for unilateral and bilateral activities was obtained by adding the tasks performed in administration one plus administration two, divided by the number of tasks performed, 17 in unilateral activities and 9 in bilateral activities.

The new motor patterns observed by the child during treatment, from INMAP, were characterized in a descriptive manner. The data obtained by the dynamometer, were calculated from a routine implemented in the Open Source Scilab software. For all evaluations, the same evaluator remained, and for the analysis of PAFT, pre and postintervention footage was used, from a blind evaluator. For the characterization of the analyzed variables, descriptive statistics were used with distribution of mean parameters, variance, and frequency, which are represented by graphs and tables for better visualization of the data.

\section{RESULTS}

This study refers to a case report of a fiveyear-old male child with a clinical diagnosis of spastic HCP on the right with left laterality. According to the degree of active movement, impairment of active movement of the upper limb was characterized as grade 2 . In Figure 3 , it can be seen that the use of the affected upper limb increased from $31.8 \%$ to $74.5 \%$, and the quality of the movement improved, from $26.3 \%$ to $71.8 \%$ when comparing the assessment pre-intervention and post-intervention; in the evaluation of one month post-intervention, they remained increased in relation to the pre-intervention evaluation, however decreased compared to the immediate post-treatment assessment, maintaining a percentage of $64.5 \%$ in the frequency of spontaneous use of the affected UL and $63.6 \%$ in the quality of movement of the same.
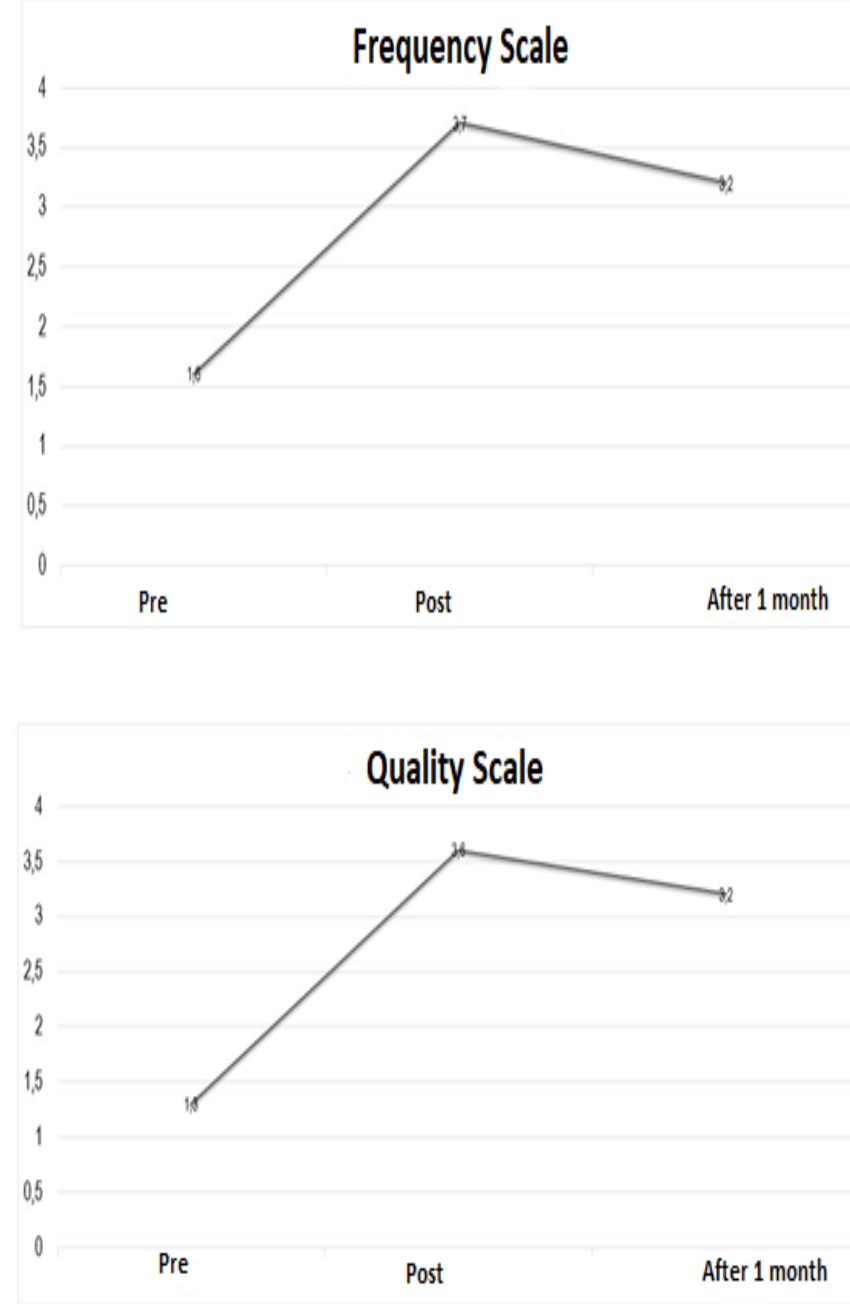

Figure 3. Scale of Frequency and Quality of Use of the PMAL throughout the evaluations.

According to Table 1 , it is noted that new motor patterns were acquired in relation to the pre-intervention evaluation and the evaluation at the end of the treatment, standing out among the unilateral activities: the abduction thumb grip, the thumb and multiple fingers opposition, the lateral clamp and an efficient clamp, weight unloading in the affected UL during the transfer from orthostatic position to sitting and weight support in the affected UL with the wrist and fingers extended, and among the bilateral tasks: the patient started to perform bimanual activities with both hands in a typical manner.

Table 2 characterizes the child's spontaneity in using the affected upper limb and if the task is performed, in addition to the functional scale score. In the three attempts to measure handgrip strength, higher mean values were noted in the post-treatment when compared to the pretreatment, these being $3.1 \mathrm{~N}$ and $2.5 \mathrm{~N}$, respectively. 
Table 1. Motor patterns observed by the child during treatment by INMAP.

\begin{tabular}{|c|c|c|c|c|c|c|c|c|}
\hline Itens & Pre & Post & Conclusion & $\begin{array}{l}\text { during unilateral a } \\
\text { the evaluations us }\end{array}$ & ing the $\mathrm{F}$ & ANT & $\begin{array}{l}\text { ities inrc } \\
\text { cale. }\end{array}$ & ighout \\
\hline 1 Reach & Yes & Yes & Maintained & & & & & \\
\hline Contact with the & Yes & Yes & Maintained & & & & & \\
\hline arm/hand & & & & Itens & Pre & & Post & \\
\hline Contact with fingers & Yes & Yes & Maintained & & Attomn & Scor & Attemn & Score \\
\hline $\begin{array}{l}\text { Contact crossing the } \\
\text { midline }\end{array}$ & Yes & Yes & Maintained & $\begin{array}{l}\text { Reach above the } \\
\text { head }\end{array}$ & $\begin{array}{l}\text { Allemp } \\
t \\
2\end{array}$ & $\begin{array}{l}\text { e } \\
3\end{array}$ & $1^{*}$ & $4^{*}$ \\
\hline $\begin{array}{l}2 \text { Hold with every } \\
\text { hand }\end{array}$ & Yes & Yes & Maintained & $\begin{array}{l}\text { Reach at waist } \\
\text { level }\end{array}$ & 1 & 3 & 1 & 3 \\
\hline $\begin{array}{l}\text { Anyway } \\
\text { Thumb in abduction }\end{array}$ & $\begin{array}{l}\text { Yes } \\
\text { No }\end{array}$ & $\begin{array}{l}\text { Yes } \\
\text { Yes }\end{array}$ & $\begin{array}{l}\text { Maintained } \\
\text { Reached }^{*}\end{array}$ & $\begin{array}{l}\text { Achieve by } \\
\text { crossing the } \\
\text { midline }\end{array}$ & 1 & 3 & 1 & $4^{*}$ \\
\hline 3 Drop objects & Yes & Yes & Maintained & Catch the ball & 1 & 4 & 1 & 4 \\
\hline Independent & Yes & Yes & Maintained & Carry the ball & 1 & 5 & 1 & 5 \\
\hline 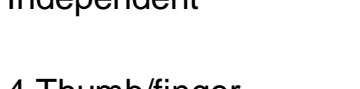 & & & 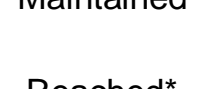 & $\begin{array}{l}\text { Putting the ball in } \\
\text { the pot }\end{array}$ & 1 & 4 & 1 & 4 \\
\hline $\begin{array}{l}4 \text { Thumb/finger } \\
\text { Multiple }\end{array}$ & $\begin{array}{l}\text { No } \\
\text { No }\end{array}$ & $\begin{array}{l}\text { Yes } \\
\text { Yes }\end{array}$ & $\begin{array}{l}\text { Reached* } \\
\text { Reached }^{*}\end{array}$ & $\begin{array}{l}\text { Pouring the ball in } \\
\text { the pot }\end{array}$ & 1 & 1 & 1 & $3^{*}$ \\
\hline $\begin{array}{l}\text { fingers/thumb } \\
\text { Lateral forceps }\end{array}$ & No & Yes & Reached* & $\begin{array}{l}\text { Throw the ball at } \\
\text { the target }\end{array}$ & 1 & 3 & 1 & 3 \\
\hline Efficient forceps & No & Yes & Reached* & Say goodbye & 1 & 3 & 1 & $4^{*}$ \\
\hline 5.Protection reaction & Yes & Yes & Maintained & $\begin{array}{l}\text { Seated protection } \\
\text { reaction }\end{array}$ & 1 & 5 & 1 & 5 \\
\hline Anterior & Yes & Yes & Maintained & $\begin{array}{l}\text { Use of finger } \\
\text { isolated }\end{array}$ & 1 & 1 & 1 & $4^{*}$ \\
\hline Lateral & Yes & Yes & Maintained & Remove fitting & 1 & 3 & 1 & 3 \\
\hline Posterior & Yes & Yes & Maintained & part by the pin & & & & \\
\hline $\begin{array}{l}6 \text { Using UL while } \\
\text { sitting }\end{array}$ & Yes & Yes & Maintained & $\begin{array}{l}\text { Holding Pencil } \\
\text { Use pencil }\end{array}$ & $\begin{array}{l}2 \\
2\end{array}$ & $\begin{array}{l}2 \\
3\end{array}$ & $\begin{array}{l}2 \\
2\end{array}$ & $\begin{array}{l}2 \\
2\end{array}$ \\
\hline Weight support on UL & No & Yes & Reached $^{*}$ & Eating a cookie & 2 & 2 & $1^{*}$ & $4^{*}$ \\
\hline Sits without support & Yes & Yes & Maintained & Eat a small piece & 1 & 3 & 1 & 3 \\
\hline $\begin{array}{l}7 \text { Use of UL in } \\
\text { crawling }\end{array}$ & Yes & Yes & Maintained & $\begin{array}{l}\text { Eating with spoon } \\
\text { Bilateral tasks }\end{array}$ & 2 & 2 & 2 & $3^{*}$ \\
\hline Diagonal pattern & Yes & Yes & Maintained & Separating a toy & 1 & 3 & 1 & 3 \\
\hline Weight support & Yes & Yes & Maintained & Carry a big ball & 1 & 4 & 1 & 3 \\
\hline 8 Weight support & No & No & Maintained & $\begin{array}{l}\text { Throw the ball } \\
\text { into the basket }\end{array}$ & 1 & 3 & 1 & $4^{*}$ \\
\hline Fist extended & No & Yes & Reached* $^{*}$ & $\begin{array}{l}\text { Putting a hat on } \\
\text { the head }\end{array}$ & 1 & 5 & 1 & 5 \\
\hline Fingers outstretched & No & Yes & Reached* & $\begin{array}{l}\text { the head } \\
\text { Put on boots }\end{array}$ & 1 & 1 & 1 & $3^{*}$ \\
\hline 9 Transitions & Yes & Yes & Maintained & To sit & 1 & 4 & 1 & 4 \\
\hline Bench press/prone & Yes & Yes & Maintained & Cat position & 1 & 3 & 1 & $5^{\star}$ \\
\hline To sit & Yes & Yes & Maintained & Crawl & 1 & 3 & 1 & $5^{*}$ \\
\hline Standing up & Yes & Yes & Maintained & $\begin{array}{l}\text { Lift using the } \\
\text { bench }\end{array}$ & 2 & 4 & $1^{*}$ & $5^{*}$ \\
\hline 10 Bilateral use & No & Yes & Reached* $^{*}$ & & & & & \\
\hline Only with help & Yes & No & Reached* & & & & & \\
\hline Typical use & No & Yes & Reached* & & & & & \\
\hline
\end{tabular}

Table 2. Child's spontaneity in performing the task with the affected limb and functional scale of the attempt to perform the task with the affected limb during unilateral and bilateral activities throughout the evaluations using the PAFT scale.

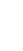




\section{DISCUSSION}

In order for gains in paretic upper limb dexterity in children with $\mathrm{CP}$ to be enhanced, the combination of techniques has been cited. In order to make better use of voluntary coordination and manual control, we seek to recognize the effect of ICT associated with the application of FB in the most affected upper limb of a child with spastic HCP. From the results obtained, there was an improvement in the quantity and quality of use of the paretic upper limb in the immediate moment of the intervention, remaining after one month of therapy; acquisitions of new motor skills and improvement in handgrip strength were also identified.

FB is described in the literature as an adjuvant technique in the rehabilitation of neurofunctional changes, with indication of its use in conventional and/or intensive methods. Among intensive rehabilitation treatments, ICT stands out for its several benefits in relation to asymmetric changes in upper limb function in neuromotor disorders. Thus, considering that the combination of these therapies acts in favor of manual functionality ${ }^{(24,39)}$, the FB concomitant with the ICT protocol may have increased the use of coordination and voluntary control ${ }^{(35)}$, for providing immediate motor sensory feedback on functional skills ${ }^{(39)}$, provide stability and protect weak structures ${ }^{(40)}$, and therefore improve the function and control of the upper extremity during rehabilitation ${ }^{(39)}$.

Once manual functionality is compromised, it is associated with numerous motor and sensory changes, which directly interfere with the child's independence and quality of life ${ }^{(17,24)}$, as a result of difficulties in using the affected upper limb to perform important daily tasks ${ }^{(17)}$. Despite its potential for use, it can be seen in the present study that the most affected limb tends to be less participatory in manual activities, whether unilateral or bilateral activities. In the adaptation process after a brain injury, the subject often does not use the affected extremity in his routine and starts to create adaptation strategies, performing his activities only with the non-paretic limb ${ }^{(41)}$.

The increase in the quality and frequency of use of the affected upper limb over the period of intervention by ICT is recognized ${ }^{(39)}$, including aspects of occupational performance, lifestyle and social participation ${ }^{(39,40)}$. The amount of initial movement compared to the final one increased, changing from rare use at the beginning of the protocol to frequent use of the most affected upper limb throughout the intervention, as well as the quality of use increased, being changed from poor to near normal. In addition, new motor patterns were observed, both in unilateral and bilateral tasks: the ability to perform efficient pinch movement; greater weight unloading in the affected UL during the transfer from the orthostatic to the sitting position; maintenance of weight support of the affected upper limb with extended wrist and fingers, among others. It is described in the literature that the persistence of the benefits of ICT associated with manual training after 6 months $^{(42,43)}$ and after 2 and 6 months $^{(19)}$ are identified for manual dexterity, quality of movement, ability to use the paretic upper limb ${ }^{(12,19,43)}$ and presence of new motor behaviors associated with greater functional independence ${ }^{(12)}$. Considering that to reduce functional limitations, ICT is based on overcoming the learned disuse ${ }^{(20)}$, especially in children and adolescents $^{(12,39,44)}$, and include concepts of neural plasticity and cortical reorganization to improve the function of the affected $\mathrm{UL}^{(44,45)}$, it is possible that there are motor gains and that they are maintained after the period of therapy.

Using transcranial magnetic stimulation and functional magnetic resonance techniques, a significant improvement in functionality is identified with the application of ICT, accompanied by activation of cortical regions adjacent to the area of the initial injury ${ }^{(37,42,43)}$, which suggests that this therapy technique can provide not only an improvement in the quality and quantity of movements, but also spontaneity of use, as well as an increase in agility and in the ability to perform functions with the UL affected by two adolescents with $\mathrm{HCP}^{(22)}$. Regarding the spontaneity of the use of the affected limb of the child evaluated in this study, greater use of the affected upper limb was observed in the periods in the comparison of the pre and post-intervention periods.

The neuromuscular capacity to generate, graduate and vary strength is essential for the formation of coordinated patterns of movement ${ }^{(44-}$ 47), when muscle tensions are higher than those experienced during daily activities, an increase in muscle strength is generated ${ }^{(45-47)}$. Among the findings, there was an increase in the handgrip strength of the compromised upper limb at the end of the three weeks of intervention. Initial strength gains, mainly in untrained subjects, are due to the increase in voluntary neural activation of trained muscles, and healthy subjects tend to have a significant increase in strength due mainly to neural aspects after 3 weeks of training, confirmed through electromyography ${ }^{(45-47)}$. 
However, despite the improvement in the study patient, the reference value of palmar pressure in the non-dominant hand of healthy children, according to the age group ${ }^{(45,46)}$ was not achieved, this difference can be explained by the reduced mobility being associated with less tension characterized by hemiparesis, which can characterize a lesser capacity to produce strength when compared to subjects without neuromotor disorders ${ }^{(45-47)}$.

\section{CONCLUSION}

An improvement in the quantity and quality of use of the paretic upper limb was observed after the application of ICT associated with FB, results that were maintained after one month of therapy. In addition, new motor skills were observed, such as thumb grip, finger opposition, tweezers, greater weight unloading and weight support with the affected upper limb, and therefore an improvement in handgrip strength. Thus, in view of the results obtained, the association of ICT and FB techniques has a potential positive effect on the handgrip strength and on the functionality and quality of use of paretic UL in children with spastic CP.

Authors' contributions: POB and LRD: Drafting of the article, review and final approval of the article. RJK and CMGM: Drafting of the article. MM: Conception and design of the article, review and final approval of the article.

Financial support: The authors declare that there was no financial support.

Conflict of interest: The authors declare that there was no conflict of interests.

\section{REFERENCES}

1. Straub K, Obrzut J. Effects of cerebral palsy on neuropsychological function. Journal of Developmental and Physical Disabilities. New York. 2009;21(9):153-167.

2. Palácio SG, Ferdinande AKS, Gnoatto FC. Análise do desempenho motor de uma crinaça com hemiparesia espástica pré e póstratamento fisioterapêutico: Estudo de caso. Cience Cuid Saude. 2008;4(1):127-31.

3. Ries LGK, Piucco EC. Martinello M. Apoio manual na cintura escapular aumenta a coativação durante o treino de marcha de crianças com paralisia cerebral. ConScientiae Saúde. 2012;11:345-52.

4. Fonseca JO, Cordani LK, Oliveira MC. Aplicação do inventário de avaliação pediátrica de incapacidade (PEDI) com crianças portadoras de paralisia cerebral tetraparesia espástica. Revista de Terapia Ocupacional da Universidade de São Paulo. 2005;16(2):67-74.

5. Brasileira IC, Moreira TMM. Prevalência de alterações funcionais corpóreas em crianças com paralisia cerebral. Acta Fisiatra 2008;11(4):37-41.

6. Vasconcelos RLM, Moura TL, Campos TF, Lindquist AR, Guerra RO. Avaliação do desempenho funcional de crianças com paralisia cerebral de acordo com os níveis de comprometimento motor. Rev Bras Fisioter. 2009;13(5):390-97.

7. Mancini MC, Alves ACM, Schaper C, Figueiredo EM, Sampaio RF, Coelho Z, et al. Gravidade da paralisia cerebral e desempenho funcional. Rev Bras Fisioter. 2004;8(3):253-60.

8. Alegretti ALC, Mancini MC, Schwartzman JS. Estudo do desempenho funcional de crianças com paralisia cerebral diparéticas espásticas utilizando o Pediatric Evaluation of Desability Inventory (PEDI). Arquivos Brasileiros de Paralisia Cerebral. 2004;1(1):35-40.

9. Erkin G, Aybay C, Kurt M, Keles I, Cakci A, Ozel $S$. The assessment of functional status in Turkish children with cerebral palsy (a preliminary study). Child Care Health Dev. 2005;31(6):719-25.

10. Donker SF, Ledebt A, Roerdink M, Sayelsberg GJP, Beek PJ. Children with cerebral palsy exhibit greater and more regular postural sway than typically developing children. Exp Brain Res. 2008;184(3):363-70.

11. Papavasiliou AS. Management of motor problems in cerebral palsy: a critical update for the clinician. Eur $\mathrm{J}$ Paediatr Neurol. 2008;13(5):387-96.

12. DeLuca SC, Echols K, Ramey SL, Taub E. Pediatric constraint-induced movement therapy for a Young child with cerebral palsy: two episodes of care. Phys Ther. 2003;83(11):100313.

13. Dromerick AW, Lang CE, Birkenmeier $R L$, Wagner JM, Miller JP, Videen TO, et al. Very Early Constraint-Induced Movement during Stroke Rehabilitation (VECTORS): A Single Center RCT. Neurology. 2009;73(3):195-201.

14. Fonseca CS; Guarany NR. A intervenção por terapia de contensão induzida no desempenho ocupacional de crianças com paralisia cerebral. Rev Interinst Bras Ter Ocup. 2018;2(2):292-304.

15. Taub E, Ramey SL, DeLuca S, Echols K. Efficacy of constraint-induced movement therapy for children with cerebral palsy with 
asymmetric motor impairment. Pediatrics. 2004;113(2):305-12.

16. Sutcliffe TL, Gaetz WC, Logan WJ, Cheyne DO, Fehlings DL. Cortical reorganization after modified constraint-induced movement therapy in pediatric hemiplegic cerebral palsy. J Child Neurol. 2007;22(11)1281-87.

17. Nascimento LR, Gloria AE, Habib ES. Effects of constraint- induced movement therapy as a rehabilitation strategy for the affected upper limb of children with hemiparesis: systematic review of the literature. Rev Bras Fisioter. 2009;13(2):97-102.

18. Tonús D, Queiroz LF. Aplicação da Terapia de Contensão Induzida com protocolo adaptado para atendimento domiciliar e suas contribuições no quadro motor e na reabilitação de paciente pós-acidente vascular encefálico. Cad Ter Ocup UFSCar. 2015;23(3):543-52.

19. Eliasson AC, Sundholm LK, Shaw K, Wang C. Effects of constraint-induced movement therapy in young children with hemiplegic cerebral palsy: an adapted model. Dev Med Child Neurol. 2005;47(4):266-75.

20. Deluca SC, Echols K, Law CR, Ramey SL. Intensive pediatric constraint-induced therapy for children with cerebral palsy: randomized, controlled, crossover trial. J Child Neurol. 2006;21(11):931-8.

21. Charles J, Lavinder G, Gordon A. Effects of constraint-induced therapy on hand function in children with hemiplegic cerebral palsy. Pediatric Physical Therapy. 2001;13(2): 68-76.

22. Garcia JM, Knabben RJ, Pereira ND, Ovando AC. Terapia por Contensão Induzida (TCl) em adolescentes com hemiparesia espástica: relato de caso. Fisioter Mov. 2012;25(4):895-906.

23. Charles JR, Wolf SL, Schneider, JA, Gordon AM. Efficacy of a child-friendly form of constraint-induced movement therapy in hemiplegic cerebral palsy: a randomized control trial. Dev Med Child Neurol. 2006;48(8):635-42.

24. Martins JS, Dos Santos LF, Castagna L. O uso da terapia por contensão induzida em sujeitos com paralisia cerebral: uma revisão de literatura. Cinergis. 2015;16(3):214-20.

25. Marques RNB, Magesto AC, Garcia RE, Oliveira CB, Matuti GS. Efeitos da terapia por contensão induzida nas lesões encefálicas adquiridas. Fisioterapia Brasil. 2016;17(1):30-6.

26. Mazzone S, Serafini A, Losa M, Aliberti MN, Gobbetti T, Paolucci S, Morelli D. Functional taping applied to upper limb of children with hemiplegic cerebral palsy: a pilot study. Neuropediatrics. 2011;42(6):249-53.
27. Mota D VN, Silva LVC. Use of functional bandages in patients with stroke. Fisioter Mov. 2014;27(3):329-36.

28. Ramírez JO, Cruz SP. Therapeutic effects of kinesio taping in children with cerebral palsy: a systematic review. Arch Argent Pediatr. 2017;115(6):e356-e361.

29. Souza Júnior RR, Lima $P$, Silva JN, Vaz DV. Effects of kinesiology taping in children with cerebral palsy: a systematic review. Fisioter Mov. 2017;30(Suppl 1):S373-82.

30. Jaraczewska E, Long C. Kinesio taping in stroke: improving functional use of the upper extremity in hemiplegia. Topics in Stroke rehabil. 2006;13(3):31-42.

31. Winstein CJ, Miller JP, Blanton S, Taub E, Uswatt G, Morris D, et al. Methods for a multisite randomized trial to investigate the effect of constraint-induced movement therapy in improving upper extremity function among adults recovering from a cerebrovascular stroke. Neurorehabil Neural Repair. 2003;17(3):137-52.

32. Bellace JV, Healy D, Besser MP, Byron T, Hohman L. Validity of the dexter evaluation system's Jamar dynamometer attachment for assessment of hand grip strength in a normal population. J Hand Ther. 2000;13(1):46-51.

33. Figueiredo IM, Sampaio RF, Mancini MC, Silva FCM, Souza MAP. Teste de força de preensão utilizando o dinamômetro Jamar. Acta Fisiatr. 2007;14(2):104-10.

34. Morris DM, Taub E, Mark VW. Constraintinduced movement therapy: characterizing the intervention protocol. Eura Medicophys. 2006;42(3):257-68.

35. Santos JCC, Giorgetti MJS, Torello EM, Meneghetti $\mathrm{CHZ}$, Ordenes IEU. A influência da Kinesio Taping no tratamento da subluxação de ombro no Acidente Vascular Cerebral. Rev Neurocienc. 2010;18(3):335-40.

36. Wittenberg GF, Chen R, Ishii K, Bushara KO, Taub E, Gerber LH, et al. Constraint-induced therapy in stroke: magnetic-stimulation motor maps and cerebral activation. Neurorehabil Neural Repair. 2003;17(1):48-57.

37. Levy CE, Nichols DS, Schmalbrock PM, Keller $P$, Chakeres DW. Functional MRI evidence of cortical reorganization in upper-limb stroke hemiparesis treated with constraint-induced movement therapy. Am J Physl Medl Rehabil. $2001 ; 80(1): 4-12$.

38. Iosa M, Morelli D, Nanni MV, Veredice C, Marro $\mathrm{T}$, Medici $\mathrm{A}$, et al. Functional taping: a promising technique for children with cerebral palsy. Dev Med Child Neurol. 2010;52(6):587-89. 
39. Baleotti LR, Gritti CC, Silva BDC. Efeitos de um protocolo modificado da terapia por contensão induzida em criança com paralisia cerebral hemiparética. Rev Ter Ocup Univ. 2014;264271

40. Levy CE, Nichols DS, Schmalbrock PM, Keller $P$, Chakeres DW. Functional MRI evidence of cortical reorganization in upper-limb stroke hemiparesis treated with constraint-induced movement therapy. Am J Physl Medl Rehabil. $2001 ; 80(1): 4-12$.

41. Sakzewski L, Ziviani J, Boyd R. Systematic review and meta-analysis of therapeutic

management of upperlimb dysfunction in children with congenital hemiplegia Pediatrics 2009;123(6):e1111-22.

42. Soares AV, Kerscher C, Uhlig L, Domenech SC, Júnior NGB. Dinamometria de preensão manual como parâmetro de avaliação funcional do membro superior de pacientes hemiparéticos por acidente vascular cerebral. Fisioter Pesq. 2011;18(4):359-64.
43. Yasukawa A, Patel P, Sisung C. Pilot study: Investigating the effects of Bandagem funcional $\AA$ in an acute pediatric rehabilitation setting. Am Jf Occup Ther. 2006;60(1):104-10.

44. Brentano MA, Pinto RS. Adaptações neurais ao treinamento de força. RBAFS. 2012;6(3):65-77.

45. Riberto M, Monroy HM, Kaihami HN, Otsubo PPS, Battistella LR. A terapia de restrição como forma de aprimoramento da função do membro superior em pacientes com hemiplegia. Acta Fisiatr 2005;12(1):15-19.

46. Liepert J, Bauder H, Miltner WH, Taub E, Weille C. Treatment-induced cortical reorganization after stroke in humans. Stroke. 2000;31(6):1210-16.

47. Wittenberg GF, Chen R, Ishii K, Bushara KO, Taub E, Gerber LH, et al. Constraint-induced therapy in stroke: magnetic-stimulation motor maps and cerebral activation. Neurorehabil Neural Repair. 2003;17(1):48-57. 